\section{THE DEPENDENCE OF CATHODIC PRE- TREATMENT ON H-TERMINATED DIAMOND SURFACE FOR DIFFERENT DOPING LEVELS}

\author{
M.R. Baldan, F. Decker, A.F. Azevedo, J.T. \\ Matsushima, N.G. Ferreira \\ Laboratório Associado de Sensores e Materiais, \\ INPE, 12245-970, S J Campos, SP Brazil
}

The electrochemical behavior of boron doped polycrystalline diamond (BDD) electrodes strongly depend on its surface properties such as the grain size, crystallographic orientation and $\mathrm{sp}^{2}$ content at the film grain boundary. The cause of different electrochemical behaviors corresponding to different surface-terminated diamond films is far from being clarified $[1,2]$. So, complementary studies are justified to correlate the electrode response and its surface termination evolution taking into account how the doping levels may influence the diamond surface after cathodic treatment (CT). This study is presented for BDD electrodes produced at four different doping levels, called as A,B,C and D, with acceptor concentrations of $10^{18}$ up to $10^{20}$ atoms. $\mathrm{cm}^{-3}$. This range was estimated from Mott-Schottky plots using frequencies of 1,10 and 50 $\mathrm{kHz}$.

The films were prepared by hot filament CVD technique using the standard mixture of $\mathrm{H}_{2} / \mathrm{CH}_{4}$ with an additional $\mathrm{H}_{2}$ flux passing through a bubbler containing different concentrations of $\mathrm{B}_{2} \mathrm{O}_{3}$ dissolved in methanol. Diamond quality, morphology and crystallinity were characterized by scanning electron microscopy, Raman spectroscopy and x-ray diffraction techniques while the changes in film surfaces were analyzed by contact angle, cyclic voltammetry and synchrotron X-ray photoelectron spectroscopy (XPS). The cathodic pretreatment was performed in $0.5 \mathrm{~mol} \mathrm{~L}^{-1} \mathrm{H}_{2} \mathrm{SO}_{4}$ at $-3.0 \mathrm{~V}$ $\mathrm{x} \mathrm{Ag} / \mathrm{AgCl}$ for $30 \mathrm{~min}$. The BDD hydrophobicity, reversibility, work potential window characteristics, as a function of the doping level, were related with its physical properties and its chemical surface; mainly associated with its natural oxidation (as-grown BDD) or with its changed behavior forced by the cathodic pretreatment.

The relationship between the BDD electrochemical response and its surface bond termination is presented comparing Mott-Schottky plots (MSP) and XPS for the lightly $\left(10^{17}\right.$ - electrode A) and heavily $\left(10^{20}\right.$ - electrode D) BDD films. Figure 1 shows the MSP obtained before and after the $\mathrm{CT}$ in $0.5 \mathrm{~mol} \mathrm{~L}^{-1} \mathrm{H}_{2} \mathrm{SO}_{4}$ at $1 \mathrm{kHz}$ for these two samples. The measurements revealed a classical Mott-Schottky behavior. The two samples presented a small shift to more negative values for flat band potentials after the cathodic polarization. The space charge density values determined after treatments for both samples are very similar to those previously measured on the as-grown electrodes.

The proportions of $\mathrm{C} 1 \mathrm{~s}$ and $\mathrm{O} 1 \mathrm{~s}$ contributions for BDD as-deposited and electrochemically treated are presented in Tables 1 and 2. These values were obtained by peak fitting to identify the presence of different chemical states in the electrode surfaces. For C1s spectra, the more intense peak was centered at $284.8 \mathrm{eV}$ attributed to the bulk diamond component. Considering the $\mathrm{C} 1 \mathrm{~s}$ region spectra the peaks studied were $\mathrm{C}-\mathrm{Hx}$ (polyhydride), "C-O" (hydroxyl or ether groups), and " $\mathrm{C}=\mathrm{O}$ " (carbonyl, carboxylic or ester carbon). These asgrown BDD films may be considered as hydrogen terminated since the $\mathrm{O}_{1 \mathrm{~s}} / \mathrm{C}_{1 \mathrm{~s}}$ ratio is smaller than 2.0 at. $\%$. Nonetheless, after CT the oxygen amount increased for the all samples, with a higher content for film D. This behavior is explained by the natural oxidation of diamond after the acid etching process that may expose more active sites in the $\mathrm{sp}^{2}$ content at the diamond grain boundary, mainly for heavily doped films.

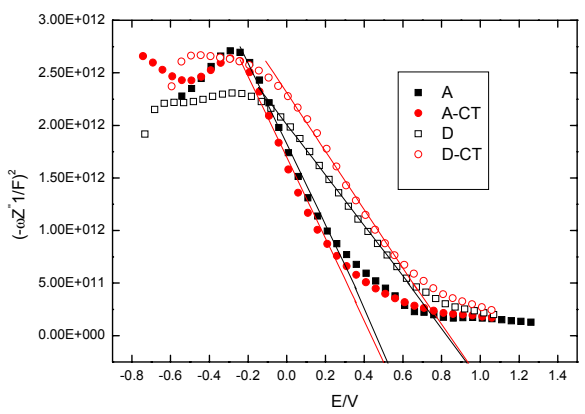

Fig. 1. Mott-Schttky representations of BDD electrodes before and after cathodic treatment.

\begin{tabular}{|c|c|c|}
\hline & $\mathrm{A}$ & $\mathrm{D}$ \\
\hline as-grown & 1.18 & 2.68 \\
\hline CT & 8.8 & 9.5 \\
\hline
\end{tabular}

Table 1. Oxygen relative proportion O1s/C1s (\%) from XPS measurements

\begin{tabular}{|c|c|c|}
\hline & A & D \\
\hline As-grown & 5.7 & 8.4 \\
\hline CT & 12 & 14.2 \\
\hline
\end{tabular}

Table 2. Proportions of "C-O" (hydroxyl or ether groups) contribution by peak fitting of $\mathrm{C} 1 \mathrm{~s}(\%)$

[1] P.Actis, A. Denoyelle, R. Boukherroub, S. Szunerits, Electrochem. Commun., 10 (2008) 402.

[2] H. Girard, N. Simon, D. Ballutaud, M. Herlem, A. Etcheberry, Diam. Rel. Mat., 16 (2007) 316. 